\title{
A Novel Circular Slotted Microstrip-Fed Patch Antenna with Three Triangle Shaped Defected Ground Structure for Multiband Applications
}

\author{
Akanksha Jaiswal", R.K. Sarin, Balwinder Raj and Shikha Sukhija \\ Department of Electronics and Communication Engineering, Dr. B. R. Ambedkar National Institute of Technology \\ Jalandhar, 144011, India \\ *corresponding author, E-mail: akankshajaiswal168@gmail.com
}

\begin{abstract}
In this paper, a novel circular slotted rectangular patch antenna with three triangle shaped defected ground structure (DGS) has been proposed. In this work, an antenna of size $38 \times 25 \mathrm{~mm}^{2}$ is presented. To make the radiating patch, the circular slots of radius $3 \mathrm{~mm}$ have been cut from the three sides, i.e., left, right, and upper, and also from the centre of the conventional rectangular patch. Three triangle shaped defects have been etched from the ground plane. Optimization has also been performed on the designed antenna to have higher bandwidth, lower return loss, and better impedance matching. Three impedance bandwidths of $0.957 \mathrm{GHz}, 0.779 \mathrm{GHz}$, and $0.665 \mathrm{GHz}$ with resonant frequencies at $3.33 \mathrm{GHz}, 6.97 \mathrm{GHz}$, and $8.59 \mathrm{GHz}$, respectively have been obtained. For the testing of proposed antenna, a prototype has been fabricated. It is observed that the results obtained with simulated and fabricated antennas are comparable. The proposed antenna design can be used for wireless and future $5 \mathrm{G}$ applications.
\end{abstract}

\section{Introduction}

With the rapid increase in the demand of wireless communication and evolution in the technology, antenna design has become more challenging due to the requirement of miniaturized antenna to make it compatible with integrated circuits. The microstrip patch antenna has gained much importance due to its inherent properties and it is probably the most widely used antenna in today's wireless world. It has various advantages such as low profile, light weight, less cost, easy fabrication process, compatibility with microwave integrated circuits (MIC's), and ease of installation on rigid surfaces [1]. Besides these advantages, microstrip patch antenna has some limitations like smaller bandwidth, less efficiency, low gain, and surface wave excitation [2]. Bandwidth enhancement is required for most of the practical applications due to large traffic volume, higher indoor or hotspot traffic, huge number of subscribers, and for efficient spectrum utilization. To fulfil these requirements, antenna miniaturization and multifrequency antenna designs have gained much interest over the past few years [3-4]. Antenna miniaturization can be obtained at the expense of its bandwidth. Thus, the difficulty in antenna design challenges engineers to not only reduce the antenna size, but also to increase the bandwidth.
Amongst the several known techniques, DGS is preferred as it is the most effective and simple technique to reduce the antenna size and also to achieve the additional resonance modes [5-8]. DGS also suppresses the spurious radiation and the surface waves which results in excellent antenna performance. It provides various advantages like higher gain, less return loss, higher operating bandwidth, compact antenna size, and rejection of undesired frequencies [9]. Due to these properties, DGS is the hotspot research topic in the field of microwave antenna designs. Recently, various patch antenna designs which utilize DGS for Wi-MAX (3.3-3.7 GHz band), WLAN (5.15-5.825 $\mathrm{GHz}$ band), and UWB (3.1-10.6 GHz band) applications have been reported [10-19]. Some printed antenna schemes with DGS have been reported which are useful for both WLAN and Wi-MAX applications [10-14]. Most of these antenna designs have a tri-band configuration by etching defects from the ground plane. In [11], a compact tri-band antenna has been proposed which uses a circular ring embedded with Y-shaped strip for patch structure with cambered defected ground structure to obtain three resonance modes with excellent impedance bandwidth for WLAN and Wi-MAX applications. A few antenna designs incorporated with DGS have been reported for UWB applications [15-19]. In [16], a compact tri-band printed antenna for UWB application has been presented. It uses Ushaped defected ground and $\mathrm{H}$-shaped slotted patch to obtain a tri-band notch characteristics.

International Telecommunication Union Radio Standard sector (ITU-R) has approved the next generation of International Mobile Telecommunication systems IMT2020 (5G) to meet the future requirements of mobile communication networks [20-21]. Realization of 5G network will include a combine structure of long term evolution (LTE) developed systems with new radio-access technologies. 5G will provide efficient spectrum utilization by extending the frequency range used for mobile communication. It will include the existing spectrum below $6 \mathrm{GHz}$ as well as the higher frequency bands above $6 \mathrm{GHz}$ [20].

In this paper, a compact tri-band microstrip patch antenna which can be used for wireless and future $5 \mathrm{G}$ applications has been proposed. Circular slots have been cut from the conventional rectangular patch structure and 
instead of using a solid ground plane, three triangle shaped defects have been incorporated on the ground plane. The proposed antenna is simple and compact in size $\left(38 \times 25 \mathrm{~mm}^{2}\right)$. The slots on the radiating patch element and triangle shaped defects on the ground layer aimed to reduce the size of the antenna and provide additional resonant modes with higher impedance bandwidth over the operating bands.

The rest of the paper is organized as follows: The Proposed Antenna Design structure and its parameters are provided in Section 2. The Results and Discussions are provided in Section 3 followed by a Conclusion in Section 4.

\section{Proposed antenna design}

The design configuration of the proposed antenna is given in Figure 1(a). Ground and patch have been made up of copper material and FR4-Epoxy has been selected as dielectric substrate for the proposed antenna design. Radiating patch has been made by cutting circular slots on the conventional rectangular patch structure. Slots have been cut from the three sides and centre of the patch as shown in Figure 1(b). The radius of the circular slots is ' $\mathrm{s}_{1}$ ' and the diameter of slots is ' $\mathrm{s}$ '. A quarter transformer feeding has been used to excite the antenna having a length and width, $\mathrm{l}_{2}$ and $\mathrm{w}_{\mathrm{f}}$, respectively. The radiating patch has been printed at the top of the substrate material as shown in Figure 1(c). The ground layer has been printed on the backside of the substrate material as shown in Figure 1(d). Three triangular defects have been introduced on the ground plane to achieve lower return loss, higher bandwidth, and excellent impedance matching. The size of the designed antenna is $38 \times 25 \mathrm{~mm}^{2}$. All parameters used for proposed antenna design have been provided in the Table 1 .

Table 1: Proposed antenna design parameters

\begin{tabular}{|c|l|c|l|}
\hline Parameter & Size & Parameter & Size \\
\hline $\mathrm{W}$ & $25 \mathrm{~mm}$ & $\mathrm{~L}$ & $38 \mathrm{~mm}$ \\
\hline $\mathrm{w}_{1}$ & $14 \mathrm{~mm}$ & $\mathrm{l}_{1}$ & $20 \mathrm{~mm}$ \\
\hline $\mathrm{L}_{\mathrm{g}}$ & $9.75 \mathrm{~mm}$ & $\mathrm{w}_{\mathrm{f}}$ & $1.6 \mathrm{~mm}$ \\
\hline $\mathrm{l}_{2}$ & $11 \mathrm{~mm}$ & $\mathrm{w}_{2}$ & $14.7 \mathrm{~mm}$ \\
\hline $\mathrm{s}_{1}$ & $3 \mathrm{~mm}$ & $\mathrm{~s}$ & $6 \mathrm{~mm}$ \\
\hline $\mathrm{a}$ & $4 \mathrm{~mm}$ & $\mathrm{~b}$ & $4.47 \mathrm{~mm}$ \\
\hline $\mathrm{c}$ & $5 \mathrm{~mm}$ & $\mathrm{~d}$ & $4.71 \mathrm{~mm}$ \\
\hline $\mathrm{l}_{3}$ & $4 \mathrm{~mm}$ & $\mathrm{~h}$ & $1.6 \mathrm{~mm}$ \\
\hline
\end{tabular}

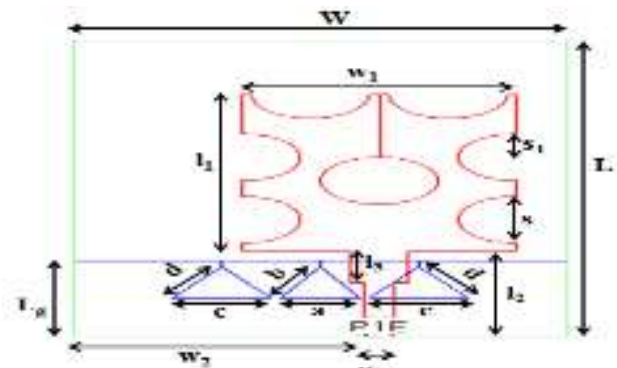

(a) ${ }^{w_{1}}$

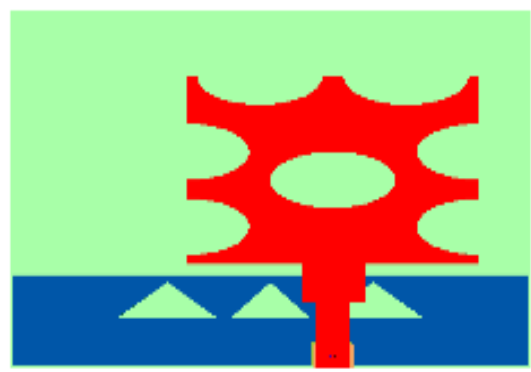

(b)

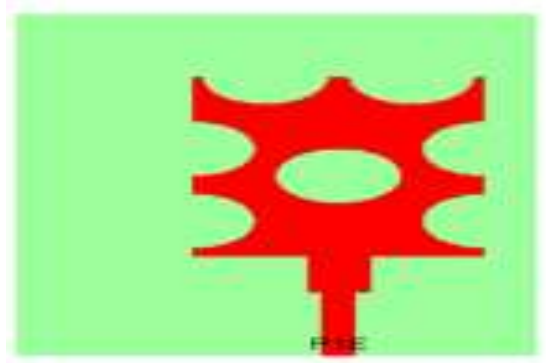

(c)

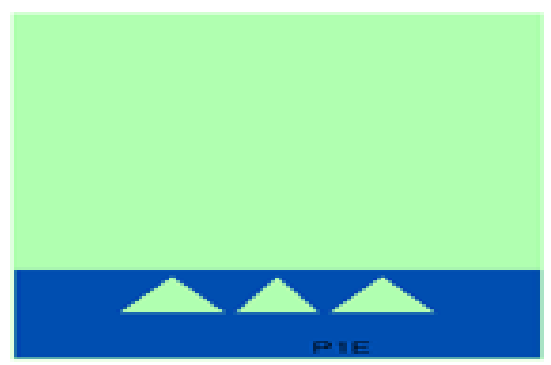

(d)

Figure 1: (a) Proposed antenna design configuration (b) 3-D view (c) Top view (d) Bottom view

\section{Results and Discussions}

In this work, the antenna has been designed using Empire XCcel 5.51 software which is a 3-D electromagnetic simulation tool based on finite difference time domain (FDTD) method. In Section 3.1, step by step evolution of the proposed antenna design and its effect on the simulated return loss has been provided. The effect of etching DGS on the simulation results has also been analysed by comparing antenna design without and with DGS. For validation purpose, a prototype has also been fabricated and its measured results are compared with the results obtained by 
simulation. The measurement of the fabricated prototype has been conducted using Vector Network Analyzer Agilent (VNA) N5230A which covers a frequency range of $10 \mathrm{MHz}$ to $20 \mathrm{GHz}$.

\subsection{Steps evolution of the proposed antenna design}

The steps involved in the proposed antenna design structure are as follows:

Step 1: The designing process starts with an antenna design having a rectangular patch and ground structure as shown in Figure 2(a). The return loss plot of this antenna is shown in Figure 2(b). It can be observed that this antenna has two operating bands with higher return loss and poor impedance matching.
Step 2: The circular slots of radius $3 \mathrm{~mm}$ have been cut from the three sides and center of the rectangular patch structure as shown in Figure 3(a). It is observed from Figure 3(b), by cutting circular slots on the rectangular patch, the antenna excites a third resonant mode and size of the patch has been reduced. But, the impedance matching is still poor for the second and third band.

Step 3: At this stage, a triangle shaped defect has been introduced on the bottom ground layer under the $50 \mathrm{ohm}$ microstrip feed as shown in Figure 4(a). By introducing a triangle shaped defect on the ground plane, it is observed that the first two bands have a lower return loss and better impedance matching. On the other hand, the third band has still poor impedance matching as illustrated in Figure 4(b).

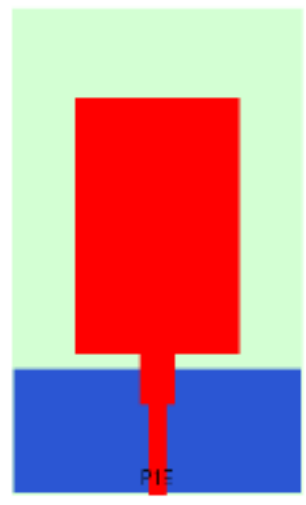

(a)

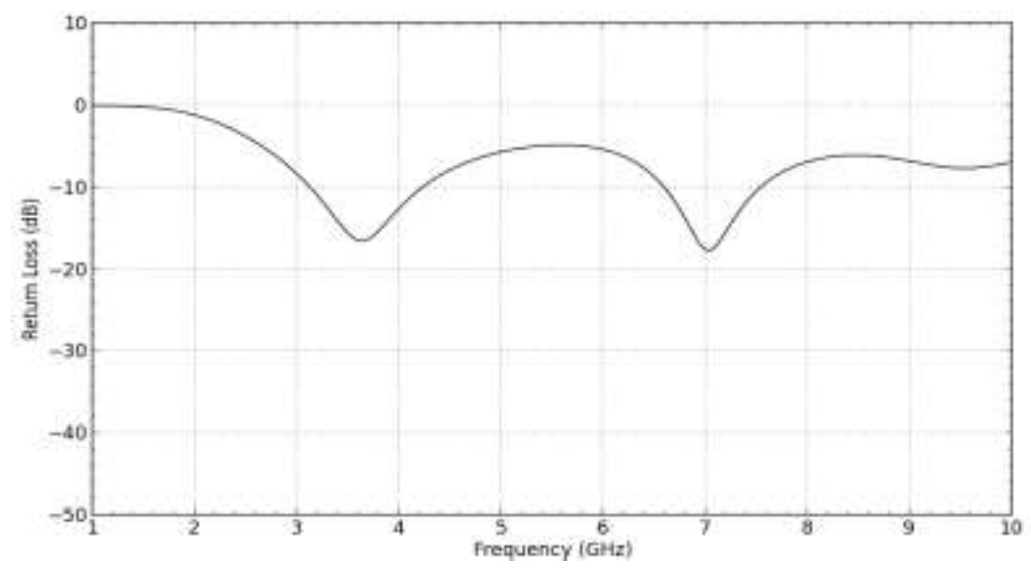

(b)

Figure 2: (a) Rectangular patch antenna and (b) its return loss (simulated)

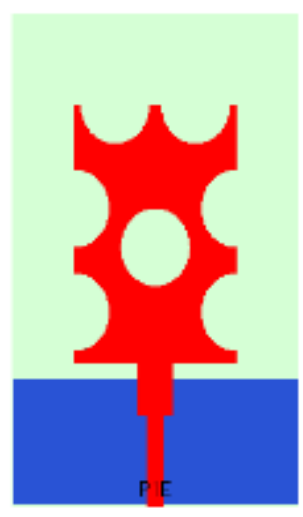

(a)

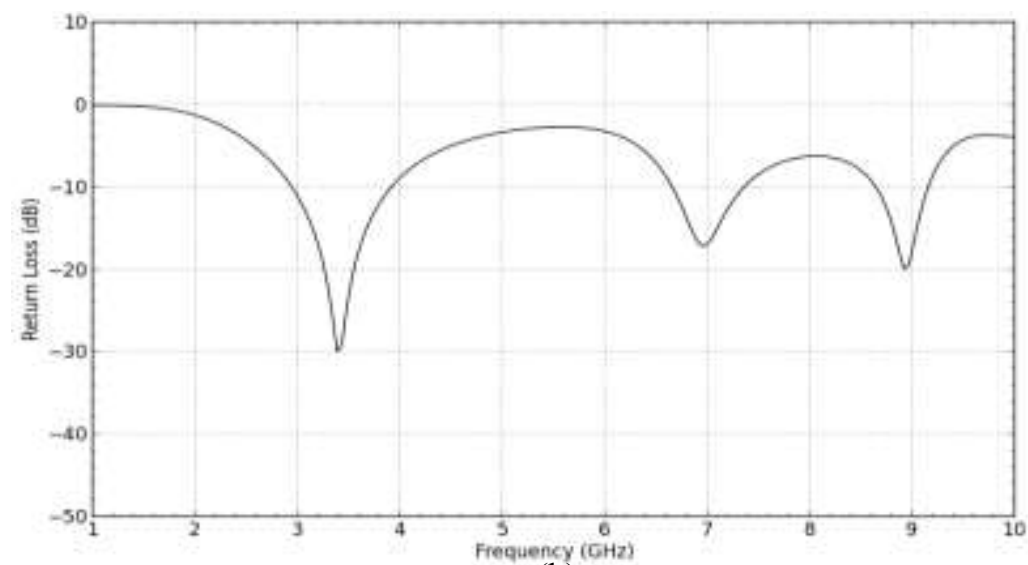

(b)

Figure 3: (a) Circular slotted patch antenna and (b) its return loss (simulated) 


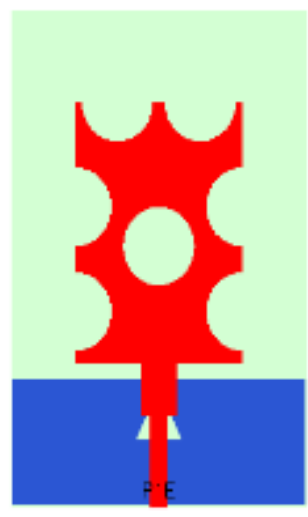

(a)

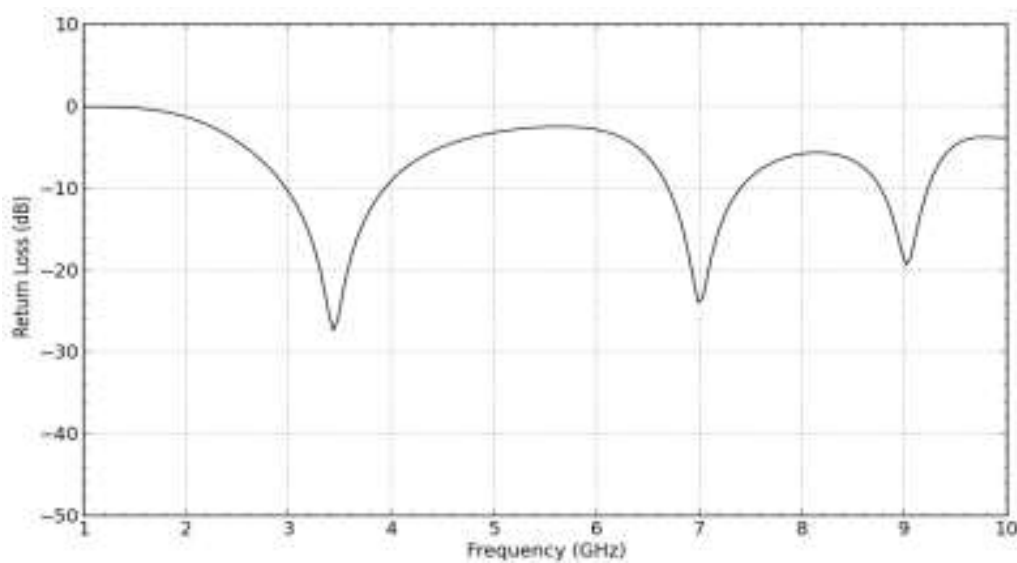

(b)

Figure 4: (a) Antenna with one triangle shaped defect and (b) its return loss (simulated)

Step 4: Further, two more symmetrical triangle shaped defects as shown in Figure 5(a) have been etched from the ground plane to increase the matching of the third band. The simulated result by introducing these defects can be seen in Figure 5(b). It is observed that by including these defects along with circular slotted patch, all the three bands have better impedance matching and lower return loss.
Step 5: After designing the antenna in Step 4, an optimization has been performed by shifting the patch in the $\mathrm{x}$ and $\mathrm{y}$ direction and varying the ground length in the $\mathrm{y}$ direction which provides higher bandwidth, lower return loss, and better impedance matching for all the three bands. The effect of varying ground length $\mathrm{L}_{\mathrm{g}}$ for different values $8.75 \mathrm{~mm}, 9.25 \mathrm{~mm}, 9.75 \mathrm{~mm}, 10.25 \mathrm{~mm}$, and $10.75 \mathrm{~mm}$ is shown in Figure 6(b).

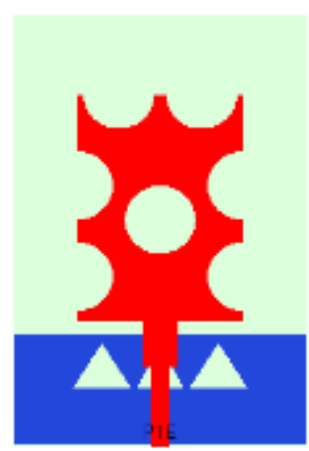

(a)

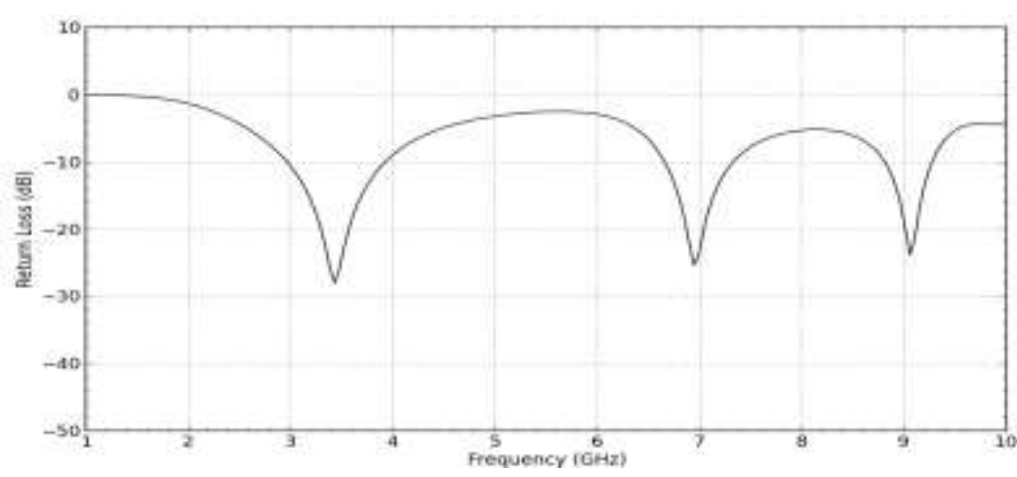

(b)

Figure 5: (a) Antenna with three triangle shaped defects and (b) its return loss (simulated)

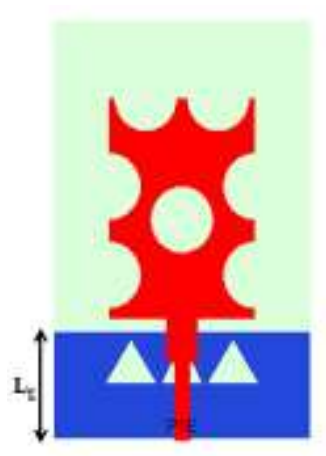

(a)

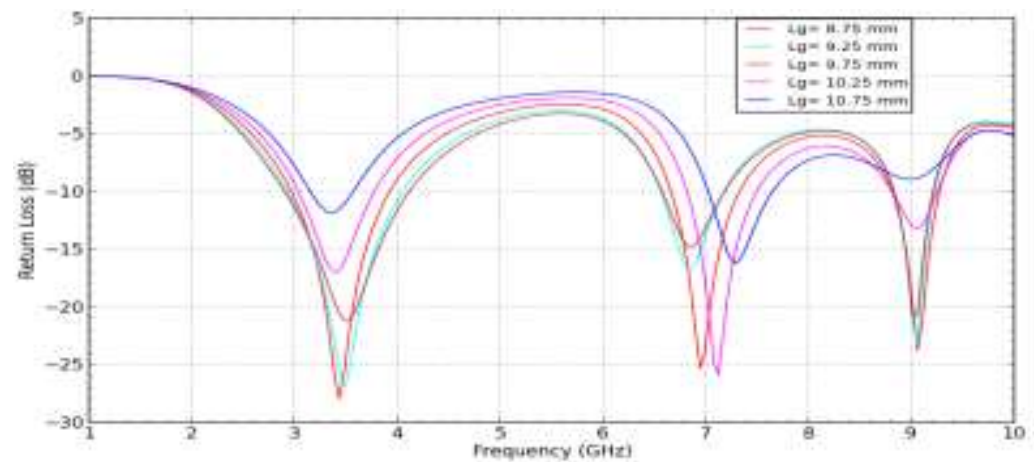

(b)

Figure 6: (a) Variation in ground length $\mathrm{L}_{\mathrm{g}}$ and (b) its corresponding optimization results 
The effect of shifting the patch in the $\mathrm{y}$ direction by changing the length $\mathrm{l}_{2}$ for different values $10 \mathrm{~mm}, 10.5 \mathrm{~mm}$, $11 \mathrm{~mm}, 11.5 \mathrm{~mm}$, and $12 \mathrm{~mm}$ is shown in Figure 7(b).

The effect of shifting the patch in the $\mathrm{x}$ direction by changing the width $\mathrm{w}_{2}$ for different values $10.7 \mathrm{~mm}, 11.7$ $\mathrm{mm}, 12.7 \mathrm{~mm}, 13.7 \mathrm{~mm}$, and $14.7 \mathrm{~mm}$ is shown in Figure 8(b).
The optimized values of $\mathrm{L}_{\mathrm{g}}, \mathrm{l}_{2}$ and $\mathrm{w}_{2}$ have been achieved as $9.7 \mathrm{~mm}, 11 \mathrm{~mm}$, and $14.7 \mathrm{~mm}$, respectively. The final proposed optimized antenna structure is shown in Figure 9(a) and its corresponding return loss is illustrated in Figure 9(b). The proposed antenna has three impedance bandwidths of $0.957 \mathrm{GHz}, 0.779 \mathrm{GHz}$, and $0.665 \mathrm{GHz}$ with resonant frequencies at $3.33 \mathrm{GHz}, 6.97 \mathrm{GHz}$, and $8.59 \mathrm{GHz}$ and return losses at these three resonant frequencies are $-40 \mathrm{~dB}$, $-43 \mathrm{~dB}$, and $-38.71 \mathrm{~dB}$, respectively.

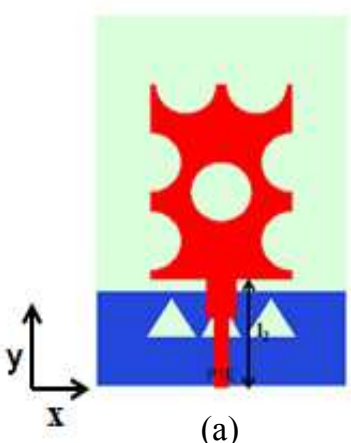

(a)

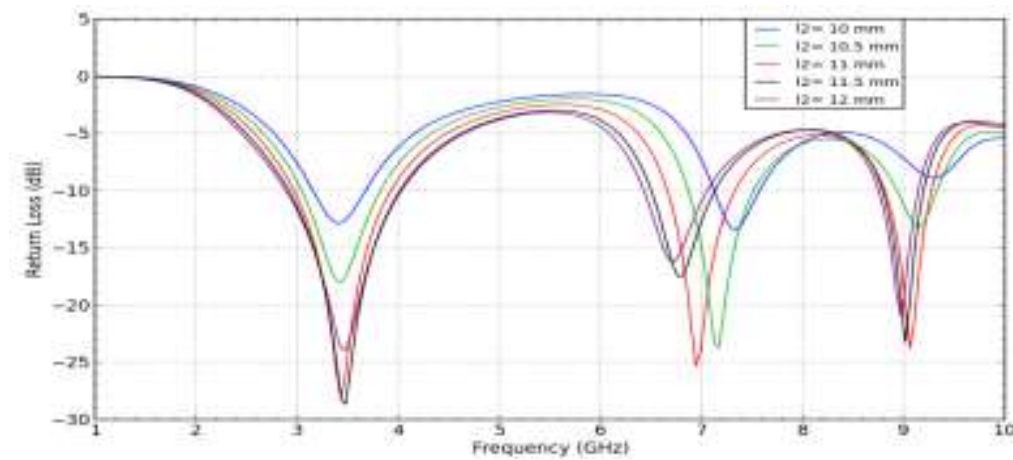

(b)

Figure 7: (a) Patch shifting in y-direction $\left(l_{2}\right)$ and (b) its corresponding optimization results

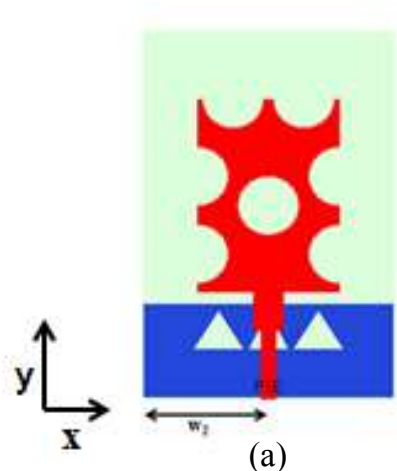

(a)

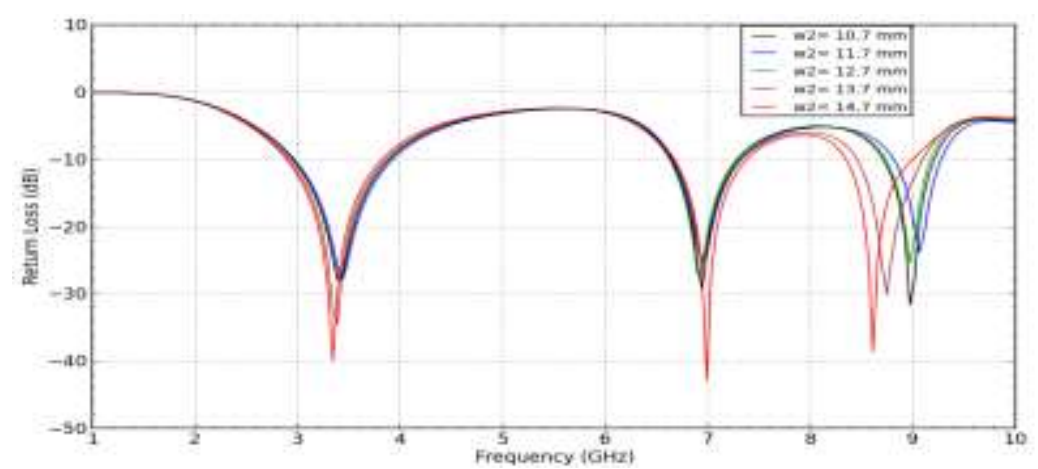

(b)

Fig.ure 8: (a) Patch shifting in $\mathrm{x}$-direction $\left(\mathrm{w}_{2}\right)$ and (b) its corresponding optimization results

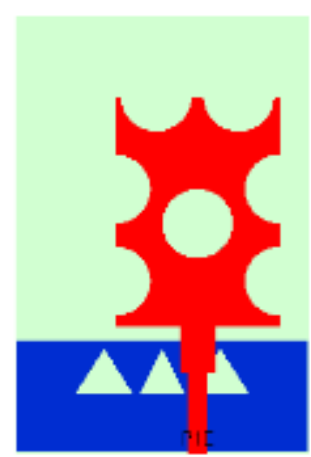

(a)

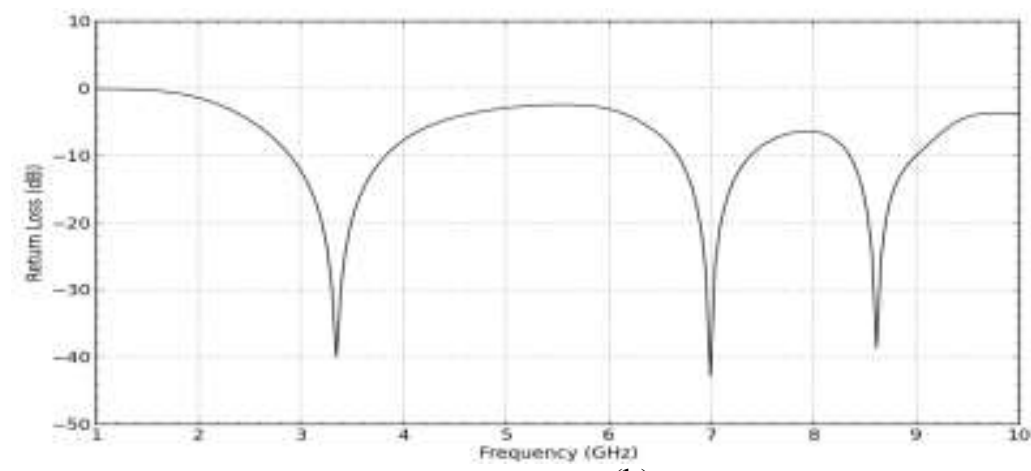

(b)

Figure 9: (a) Proposed antenna design and (b) its return loss (simulated) 
Figure 10 shows the impedance matching of the proposed antenna. It is observed that real part of the impedance is nearly $50 \Omega$ at resonant frequencies of $3.33 \mathrm{GHz}, 6.97 \mathrm{GHz}$, and $8.59 \mathrm{GHz}$, which is required for perfect matching characteristics of the antenna.

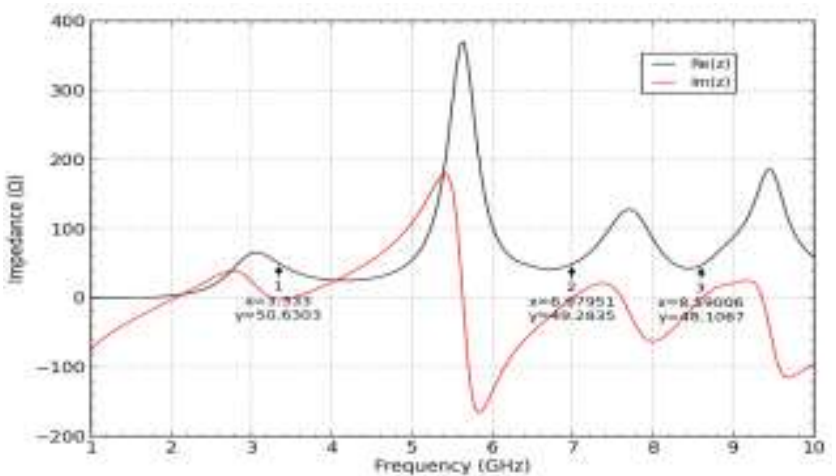

Figure 10: Simulated impedance versus frequency graph of the proposed antenna

The VSWR of the proposed antenna is shown in Figure 11. It is observed that at the three resonant frequencies, the VSWR is approximately equal to 1 which indicates maximum power delivered to the antenna and better impedance matching condition.

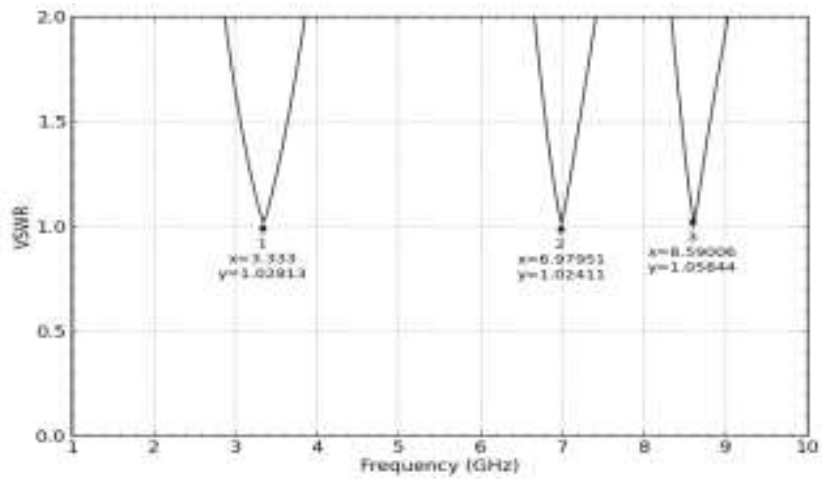

Figure 11: Simulated VSWR versus frequency graph of the proposed antenna

Figure 12 shows the simulated radiation pattern of the proposed antenna at the three resonant frequencies of 3.33 $\mathrm{GHz}, 6.97 \mathrm{GHz}$, and $8.59 \mathrm{GHz}$. It is observed that the radiation pattern in the $\mathrm{H}$-Plane (XZ-Plane) demonstrates a close omnidirectional pattern, whereas E-Plane (YZ-Plane) shows a dipole-like radiation pattern.

The return loss comparison of antenna with DGS and without DGS is shown in Figure 13. From this figure, it is observed that etching the three triangle shaped defects on the ground plane results in lower return loss as compared to the antenna without DGS

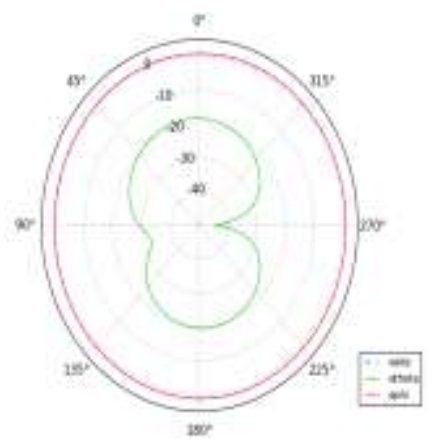

(a) $3.33 \mathrm{GHz}$ H-Plane

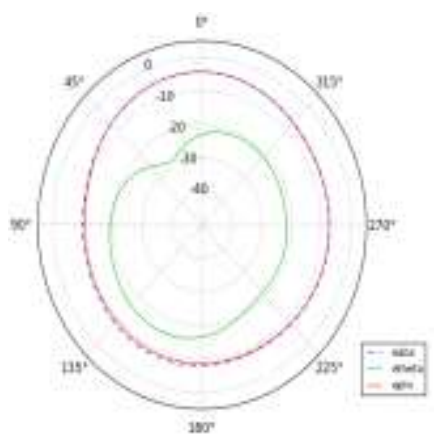

(c) $6.97 \mathrm{GHz}$ H-Plane

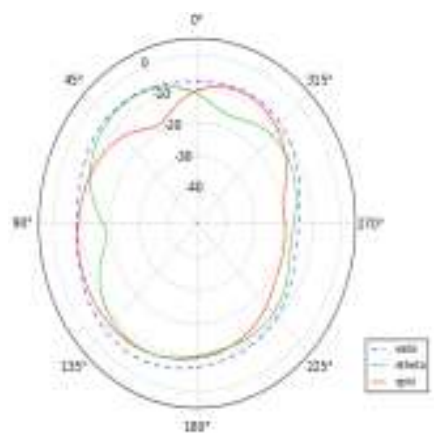

(e) $8.59 \mathrm{GHz}$ H-Plane

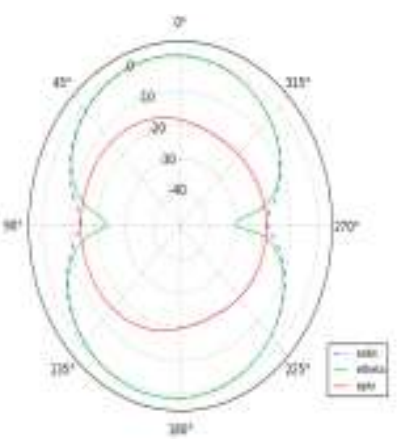

(b) $3.33 \mathrm{GHz}$ E-Plane

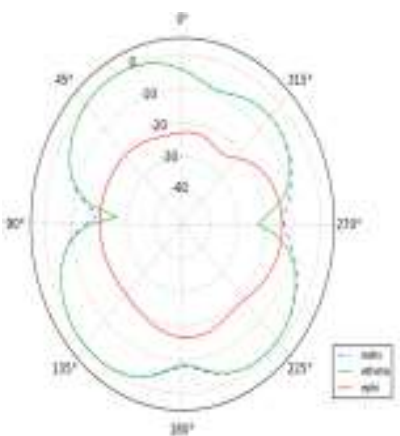

(d) $6.97 \mathrm{GHz}$ E-Plane

(f) $8.59 \mathrm{GHz}$ E-Plane

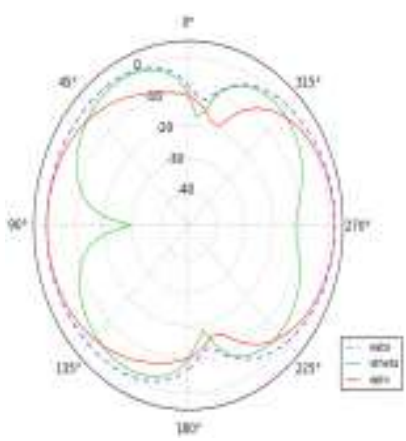

Figure 12: Simulated radiation pattern of the proposed antenna at three resonant frequencies

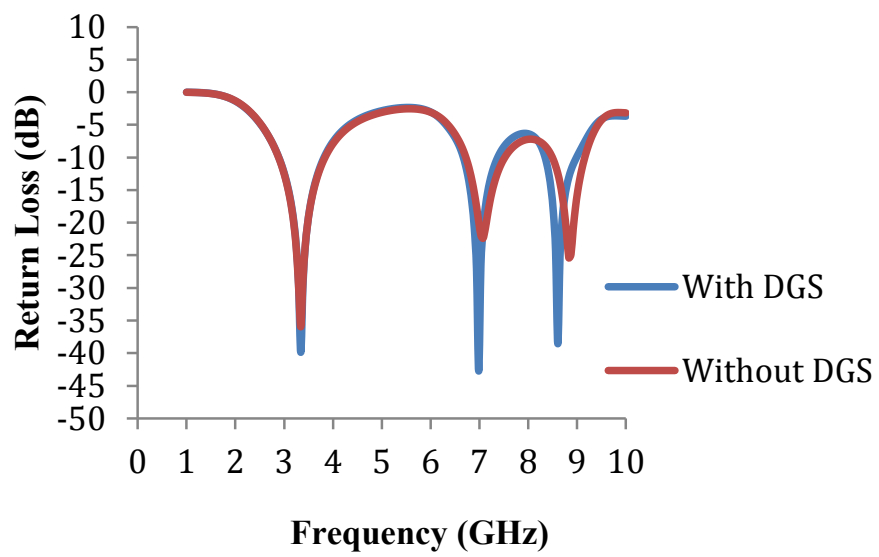

Figure 13: Return loss comparison of antenna with DGS and without DGS 


\subsection{Experimental results}

The designed antenna has been fabricated by printing and etching process. The ground and radiating patch have been etched on the opposite sides of the FR4-Epoxy substrate material having thickness $\mathrm{h}=1.6 \mathrm{~mm}$, relative permittivity $\varepsilon_{\mathrm{r}}=4.4$, and loss tangent of 0.02 and is shown in Figure 14.

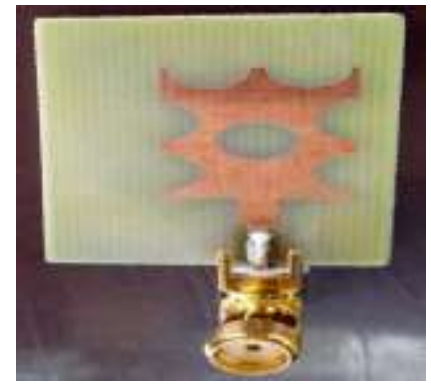

(a)

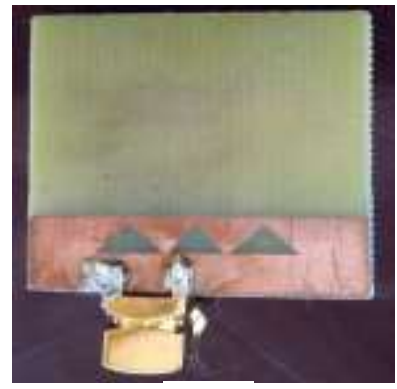

(b)
Figure 14: Fabricated prototype (a) Top view (b) Bottom view

The measurement has been carried out with the help of Vector Network Analyzer (VNA). Figure 15 shows the measured return loss of the proposed antenna. It can be observed from the figure that the fabricated antenna also exhibits tri-band structure and has three impedance bandwidths of $0.854 \mathrm{GHz}, 1.432 \mathrm{GHz}$, and $0.672 \mathrm{GHz}$ at resonant frequencies of $3.20 \mathrm{GHz}, 7.50 \mathrm{GHz}$, and $9.64 \mathrm{GHz}$, respectively. The return losses obtained for these three operating bands are $-48.43 \mathrm{~dB},-46.16 \mathrm{~dB}$, and $-39.48 \mathrm{~dB}$, respectively.

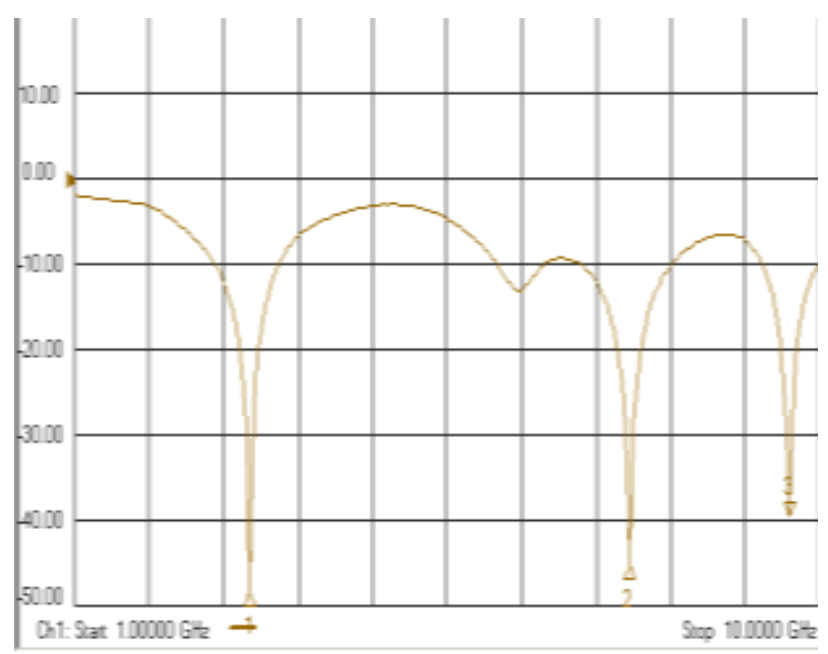

Figure 15: Measured return loss of the proposed antenna

The comparison of resonant frequency, return loss, and bandwidth of the proposed simulated and fabricated antennas are provided in Table 2. It can be observed from Table 2 that there is only slight variation in the simulated and fabricated antenna results.
Table 2: Comparison between Simulated and Measured Results

\begin{tabular}{|l|l|l|l|l|l|l|}
\hline \multirow{2}{*}{ Parameters } & \multicolumn{3}{|c|}{ Simulated } & \multicolumn{3}{c|}{ Measured } \\
\cline { 2 - 7 } & $\begin{array}{l}1^{\text {st }} \\
\text { Band }\end{array}$ & $\begin{array}{l}2^{\text {nd }} \\
\text { Band }\end{array}$ & $\begin{array}{l}3^{\text {rd }} \\
\text { Band }\end{array}$ & $\begin{array}{l}1^{\text {st }} \\
\text { Band }\end{array}$ & $\begin{array}{l}2^{\text {nd }} \\
\text { Band }\end{array}$ & $\begin{array}{l}3^{\text {rd }} \\
\text { Band }\end{array}$ \\
\hline $\begin{array}{l}\text { Resonant } \\
\text { frequency } \\
(\mathrm{GHz})\end{array}$ & 3.33 & 6.97 & 8.59 & 3.20 & 7.50 & 9.64 \\
\hline $\begin{array}{l}\text { Return loss } \\
\mathrm{S}_{11}(\mathrm{~dB})\end{array}$ & -40 & -43 & -38.71 & -48.43 & -46.16 & -39.48 \\
\hline $\begin{array}{l}\text { Bandwidth } \\
(\mathrm{GHz})\end{array}$ & 0.957 & 0.779 & 0.665 & 0.854 & 1.432 & 0.672 \\
\hline
\end{tabular}

For example, the values of resonant frequency, return loss, and bandwidth for the $1^{\text {st }}$ band of the simulated antenna are $3.33 \mathrm{GHz},-40 \mathrm{~dB}$, and $0.957 \mathrm{GHz}$, respectively, whereas, for the $1^{\text {st }}$ band of the fabricated antenna their values are $3.20 \mathrm{GHz},-48.43 \mathrm{~dB}$, and $1.432 \mathrm{GHz}$, respectively. Therefore, it is concluded that there is good agreement between the simulated and fabricated antennas.

\section{Conclusion}

A novel circular slotted rectangular patch antenna with three triangle shaped defects on the ground plane for multiband applications has been presented. The effects of varying ground and patch length dimensions have been investigated and optimized results have been reported. The circular slots on the radiating patch element and three triangle shaped defects on the ground plane result in reduced antenna size, and exhibits three resonance modes. From the simulated results, it has been concluded that by introducing circular slots on the rectangular patch and three triangle shaped defects on the ground plane; higher operating bandwidth, lower return loss, good radiation pattern and excellent impedance matching has obtained. It has also been testified that the measured results are comparable with the simulated results. The good characteristics of the designed antenna can be well suited for wireless and future $5 \mathrm{G}$ applications

\section{References}

[1]. C.A. Balanis, Antenna theory: analysis and design, John Wiley \& Sons, 2016.

[2]. A. Sharma, N.K. Atal Rai, Study of Microstrip Rectangular Patch Antenna and its various parameters, International Journal 1(2): pp. 49-51, 2013.

[3]. J.L Volakis, C.C. Chen, K. Fujimoto, Small antennas: miniaturization techniques \& applications, Vol.1. New York: McGraw-Hill, 2010.

[4]. M.U. Khan, M.S. Sharawi, R. Mittra, Microstrip patch antenna miniaturisation techniques: a review, IET Microwaves, Antennas \& Propagation 9(9): pp. 913922, 2015. 
[5]. K.H. Chiang, K.W. Tam, Microstrip monopole antenna with enhanced bandwidth using defected ground structure, IEEE antennas and wireless propagation letters, 7: pp. 532-535, 2008.

[6]. C. Kumar, D. Guha, Defected ground structure (DGS)integrated rectangular microstrip patch for improved polarisation purity with wide impedance bandwidth, IET Microwaves, Antennas \& Propagation, 8(8): pp. 589-596, 2014.

[7]. M.A. Antoniades, G.V. Eleftheriades, A compact multiband monopole antenna with a defected ground plane, IEEE Antennas and wireless propagation letters 7: pp. 652-655, 2008.

[8]. P. Singh, R. Tomar, The use of defected ground structures in designing microstrip filters with enhanced performance characteristics, Procedia Technology 17: pp. 58-64, 2014.

[9]. L.H. Weng, Y.C. Guo, X.W. Shi, X.Q. Chen, An overview on defected ground structure, Progress In Electromagnetics Research 7: pp. 173-189, 2008.

[10]. W.C. Liu, C.M. Wu, Y. Dai, Design of triple-frequency microstrip-fed monopole antenna using defected ground structure, IEEE transactions on antennas and propagation 59(7): pp. 2457-2463, 2011.

[11]. J. Pei, A.G. Wang, S. Gao, W. Leng, Miniaturized triple-band antenna with a defected ground plane for WLAN/WiMAX applications, IEEE Antennas and Wireless Propagation Letters 10: pp. 298-301, 2011.

[12]. A.K. Gautam, L. Kumar, B.K. Kanaujia, K. Rambabu, Design of compact F-shaped slot triple-band antenna for WLAN/WiMAX applications, IEEE Transactions on Antennas and Propagation 64(3): pp. 1101-1105, 2016.

[13]. D.D. Krishna, M. Gopikrishna, and C. K. Aanandan, A $C P W$-fed triple band monopole antenna for WiMAX/WLAN applications, $38^{\text {th }}$ IEEE European Conference on Microwave, EuMC 2008, pp. 897-900, 2008.

[14]. W.S. Chen, K.Y. Ku, Band-rejected design of the printed open slot antenna for WLAN/WiMAX operation, IEEE Transactions on Antennas and Propagation, 56(4): pp. 1163-1169, 2008.

[15]. K. Yin, J.P. Xu, Compact ultra-wideband antenna with dual bandstop characteristic, Electronics Letters, 44(7): pp. 453-454, 2008.

[16]. J.Y. Deng, Y.Z. Yin, S.G. Zhou, Q.Z. Liu, Compact ultra-wideband antenna with tri-band notched characteristic, Electronics Letters 44(21): pp. 12311233, 2008

[17]. A. Nouri, G.R. Dadashzadeh, A compact UWB bandnotched printed monopole antenna with defected ground structure, IEEE Antennas and Wireless Propagation Letters, 10: pp. 1178-1181, 2011.

[18]. M. Abdollahvand, G. Dadashzadeh, D. Mostafa, Compact dual band-notched printed monopole antenna for UWB application, IEEE Antennas and Wireless Propagation Letters 9: pp. 1148-1151, 2010.
[19]. X.J. Liao, H.C. Yang, N. Han, Y. Li, Aperture UWB antenna with triple band-notched characteristics, Electronics Letters, 47(2): pp. 77-79, 2011.

[20]. A.B. Ericsson, 5G Radio Access-Research and Vision, Ericsson White Paper, 284: pp. 23-3204, 2013.

[21]. S. Chen, J. Zhao, The requirements, challenges, and technologies for $5 G$ of terrestrial mobile telecommunication, IEEE Communications Magazine, 52(5): pp. 36-43, 2014. 